\title{
Global Inequities and Emissions in Western European Textiles and Clothing Consumption
}

\author{
Simon Mair ${ }^{*}$, Angela Druckman ${ }^{1}$ and Tim Jackson ${ }^{1}$ \\ 1 Centre for Environmental Strategy, Faculty of Physical and Engineering Science, University of Surrey, \\ Guildford, GU2 7JG *Corresponding author: s.mair@surrey.ac.uk; +447706785676
}

\begin{abstract}
Rising demand for cheaper textiles and clothing in Western Europe is well documented, as are changes in the Textiles and Clothing industry's globalised production structure. We apply a sub-systems global multi-regional input-output accounting framework to examine the sustainability implications of meeting Western European demand for textiles and clothing goods between 1995 and 2009. Our framework estimates environmental and socio-economic impacts of consumption in a consistent manner and shows where these occur both geographically and in the value chain. The results demonstrate that Western European textiles and clothing consumption remains dependent on low-cost labour from Brazil, Russia, India and China (BRIC), principally in the Textiles and Clothing and Agricultural sectors. Conversely, we show that the wage rate for BRIC workers in the global value chains serving Western European textiles and clothing consumption has risen over time but remains low relative to the wage rate paid to Western European workers. Likewise, we find that profits are increasingly generated within BRIC and that they are now at comparable levels to those generated in Western Europe. We find a slight overall decrease in the amount of carbon emitted in the production of textiles and clothing goods for Western Europe between 1995 and 2009. However, the trend is not linear and the importance of different underlying drivers varies over the timeseries. We conclude by discussing the implications of these results for a more sustainable future for Western European textiles and clothing consumption.
\end{abstract}

Keywords: consumption accounting; textiles \& clothing; carbon footprint; social footprint; input-output analysis; globalisation; global value chains 


\section{INTRODUCTION}

\subsection{Sustainability, Affluent Lifestyles and Macroeconomic Structures}

Sustainability means achieving a good and equitable life for all people within the ecological limits of a finite planet (Jackson, 2009, 2011). However, at present there are substantial inequities and environmental impacts embodied in the macroeconomic structures that support affluent consumer lifestyles in more economically developed countries (Alsamawi et al., 2014; Lenzen et al., 2012; Simas et al., 2014a). Key factors influencing these inequities and environmental impacts are globalisation and changes in the consumption patterns of more economically developed countries (Kanemoto et al., 2014; Simas et al., 2014a; Xu and Dietzenbacher, 2014). Textiles and clothing consumption in Western Europe is a prime example of a production-consumption system strongly affected by both changes in consumption and the geographies of production (Dicken, 2011; Dunford, 2004). Therefore, in this study we empirically examine how these factors have affected the equity and environmental impacts of global textiles and clothing production for the Western European market.

\subsection{The Textiles and Clothing Context: Globalisation, Fast Fashion and Sustainability}

In 1995 the quotas restricting world trade in textiles and clothing goods began to be formally removed. Combined with a more general globalisation process this liberalisation of trade allowed for substantial movement of low skill, labour intensive parts of textiles and clothing value chains into developing countries (Dunford, 2004; Los et al., 2014; OECD, 2004). While job creation in developing countries is generally perceived to be beneficial, there remain questions around low wage rates, poor rights for workers and unsafe working conditions (Allwood et al., 2006; International Trade Union Confederation, 2014).

The geographical shift in manufacturing is also likely to have caused a shift in the location of pollution. High level studies of global trade typically find that international trade has shifted pollution into developing countries that have used manufacturing and heavy industry to fuel their growth (Davis et al., 2011; Kanemoto et al., 2014; Peters et al., 2011b). Previous studies suggest that this could be the case for textiles and clothing consumption, reporting China to be the biggest source of carbon in the textiles and clothing value chains supplying consumers in a small sample of Western European countries (Andrew and Peters, 2013; Carbon Trust, 2011). However, these studies examine a single point in time and so it is unclear if this represents a displacement or an increase in global emissions. Likewise, we 
do not know how emissions from developing countries in textiles and clothing value chains are changing.

Furthermore, Western European textiles and clothing retailers now refresh their product lines much more frequently than in the past leading to lower prices and shorter lifetimes (Francois et al., 2007; Morris and Barnes, 2008; Schor, 2005). In turn, many brands have passed more risk and pressure to their developing country suppliers in order to further reduce both costs and lead times and thereby remain competitive (Morris and Barnes, 2008; Taplin, 2006). This has placed additional stress on already poor working conditions and is thought to have contributed to the collapse of the Rana Plaza complex (Taplin, 2014).

\subsection{Aims and Contributions}

The aim of this study is to empirically assess both socio-economic and environmental sustainability aspects of Western European textiles and clothing consumption between 1995 and 2009. In the existing literature, environmental and socio-economic impacts along textiles and clothing supply chains are largely considered separately (e.g. Carbon Trust, 2011; Chen and Burns, 2006; Claudio, 2007; Sørensen, 2008; Tokatli et al., 2011) or analysed over short periods of time (Allwood et al., 2006; Andrew and Peters, 2013). Therefore we extend the existing literature by adopting a multi-factor approach to examine changes over a 15 year period. Moreover, we investigate how changes in Western European demand for textiles and clothing goods have affected each indicator at three different scales: the sum of impacts at every stage of production (production footprints) and the impacts that occur in both specific geographical regions and specific economic sectors. By investigating multiple sustainability factors at multiple scales we are able identify both winners and losers, to find tensions between different sustainability goals, and to suggest a win-win scenario moving forwards. Furthermore, looking over a fifteen year time period provides a richer understanding of mechanisms driving changes in the textiles and clothing value chain sustainability than is possible from single point in time studies.

Finally we make two methodological contributions. First, our use of sub-systems framing to improve the robustness of Global Multi-Regional Input-Output (GMRIO) results is novel. Second, we contribute to the limited literature relating value added indicators (such as

global value chain indicators (Los et al., 2014; Timmer et al., 2013b)) and consumption based accounting. This provides a solid link between a large section of the sustainability accounting literature and the most recent empirical work on globalisation. 
The rest of the paper is structured as follows; Section 2 introduces key concepts and develops our accounting framework. Section 3 applies this framework to Western European textiles and clothing consumption and Section 4 makes suggestions for a more sustainable future for Western European Consumption of textiles and clothing. Section 5 summarises our main points and concludes.

\section{Concepts ANd Methods}

\subsection{Global Value Chains and Production Footprints}

Value chains are the networks of value adding activity taking place between conception and delivery of a product. Where supply chains emphasise physical stages of production (Timmer et al., 2013a) value chains include design, marketing and financial services etc. (Feenstra and Hanson, 1996; Timmer et al., 2013b). Because the value chains of most industries now cross multiple national boundaries (Los et al., 2014) they are referred to as Global Value Chains (GVCs).

In macro or meso economic analysis GVCs are described in terms of national final production, so that the Western European textiles and clothing GVC refers to the global network of activity leading to the final goods sold by Western European textiles and clothing firms, no matter where in the world those goods are sold. Timmer et al., (2013b) propose two new indicators to assess impacts and contributions along GVCs defined in this way: global value chain income (GVC Income) and global value chain jobs (GVC Jobs). GVC Income is defined as the sum of all gross value added generated along a given global value chain while GVC Jobs is the total employment across the global value chain. Timmer et al (2013) use GVC Income and GVC Jobs to analyse fragmentation and competitiveness of European manufacturing industries. Their analysis confirms that European nations are increasingly service focused and that manufacturing is increasingly globally distributed. GVC indicators have sustainability implications because they reveal global, geographical and sectoral patterns in income and job creation. Moreover, the concept behind GVC Income or GVC Jobs type indicators is easily extended to other social and environmental concerns: we can construct a generic GVC Indicator as the sum of any given factor, for which we have data, across a GVC.

However, while GVC Indicators have sustainability implications we are interested primarily in the role played by consumers in a particular region. This approach is known as consumption based accounting and uses carbon or labour footprints (for example, Alsamawi et al., 2014; Druckman et al., 2008; Druckman and Jackson, 2009; Wiedmann et al., 2010). 
GVC indicators assess impacts occurring in the production stages of a products lifecycle and are therefore closely related to production footprints - a form of partial footprint analogous to a cradle-to-gate Life Cycle Assessment.

Our analysis makes use of production footprints, because they place the focus on the parts of a product's lifecyle that are upstream of consumers and retailers and are therefore the most appropriate way to examine the effect of changes in consumption and globalisation on production impacts. However, it is important to note that production footprints are not directly equivalent to GVC Indicators: GVC Income for Western European textiles and clothing is equal to the income generated producing goods eventually sold by the Western European Textiles and Clothing sector to consumers, wherever they may be in the world, whilst the Western European textiles and clothing income production footprint is equal to the sum of all income generated producing Textiles and Clothing goods then purchased by Western European consumers.

Because Western European consumers purchase textiles and clothing goods from many different countries, and the Western European Textiles and Clothing sector exports goods to consumers all over the world, the Western European textiles and clothing Income production footprint will be the sum of the proportion of the Western European textiles and clothing GVC Income stimulated by Western European consumption plus the proportion of the textiles and clothing GVC Incomes in the rest of the world that are stimulated by Western European consumption (Figure 1). More generally, a production footprint is the sum of many GVC Indicators each weighted by the level of consumption of the outputs of each GVC in the region of interest.

\subsection{Sub-System Global Multi-Regional Input-Output Analysis}

The core of our analysis is a global multi-regional input-output model (GMRIO). GMRIOs capture the whole world economy through explicit modelling of the international and domestic trade networks of multiple countries (Tukker and Dietzenbacher, 2013). A standard extended ${ }^{1}$ GMRIO can be written,

$$
\mathbf{E}=\widehat{\mathbf{u}} \mathbf{L Y}
$$

\footnotetext{
${ }^{1}$ A purely economic GMRIO defines a relationship between changes in final demand and economic output. An 'extended' GMRIO is so called because it defines additional relationships between impact factors (pollution or jobs, for example) and economic output thereby allowing analysis of a greater range of problems (Miller and Blair 2009).
} 
Defining the number of countries as $c$ and the total number of sectors across all countries as $s, \mathbf{E}$ is the $s \times c$ matrix of impact (either environmental, e.g. carbon emissions; social, e.g. hours worked; or economic, e.g. profit generated). $\mathbf{L}$ is the $s \times s$ leontief inverse describing the interactions between sectors both within and between countries and $\widehat{\mathbf{u}}$ is an $s \times s$ diagonalised vector of direct impact intensities for production activity in each sector. $\mathbf{Y}$ is the $s \times c$ matrix describing final demand in each country from each sector. We use the World Input-Output database (WIOD), which has 40 countries and one Rest of the World (RoW) 'country', each with 35 sectors (see section 2.4 for more details), so $c=41$ and $s=$ 1435. For ease of exposition we write $\widehat{\mathbf{u}} \mathbf{L}=\mathbf{Q}$, so,

$$
\mathbf{E}=\mathbf{Q Y}
$$

Because input-output analysis and GMRIOs are established methods for a wide range of both environmental and socio-economic footprint analyses (Bradley et al., 2013; Miller and Blair, 2009; Moran et al., 2013; Acquaye et al., 2014; Simas et al., 2014b) the remainder of this section focuses on the adaptation required to allow robust estimates of sectoral production footprints from a GMRIO model.

The stochastic nature of uncertainty in input-output data (Acquaye et al., 2011) means that GMRIO model results are most uncertain at the individual sector level (e.g. Turkish Agriculture) and aggregation of results reduces these uncertainties (Lenzen et al., 2010; Wilting, 2012). Therefore we do not report estimates of individual sector level impacts. Rather we report results at a more aggregate level (e.g. global Agriculture or all sectors in $B R I C)$. But aggregating in this way before running an input-output model represents a loss of information which increases uncertainty in results relative to using the original data (Andrew et al., 2009; Lenzen, 2011). Therefore we follow a sub-systems (see, for example, Piaggio, 2015; Schnabl, 1995; Zhang and Chen, 2008) input-output approach and use partitioned matrices to achieve a regional breakdown of impacts without aggregating before running the model. After obtaining a set of results using the original data we then aggregate to the desired level. This approach of using all available information then aggregating the detailed results should provide the most robust analysis possible, given our research focus and dataset.

The first step is to separate WIOD's 1435 sectors into our sector category system. In our analysis we use five sector partitions but for simplicity the following exposition shows only two sector partitions - Textiles and Clothing $(\boldsymbol{t})$, which contains the 41 "Textiles and Textile Products" sectors from the WIOD table and All Other Sectors (o) which contains the remaining 1394 sectors. Partitioning equation (2) in this way gives, 


$$
\left[\begin{array}{c}
\mathbf{E}^{\mathbf{t}} \\
\mathbf{E}^{\mathbf{o}}
\end{array}\right]=\left[\begin{array}{ll}
\mathbf{Q}^{\mathbf{t}, \mathbf{t}} & \mathbf{Q}^{\mathbf{t}, \mathbf{o}} \\
\mathbf{Q}^{\mathbf{o}, \mathbf{t}} & \mathbf{Q}^{\mathbf{o}, \mathbf{o}}
\end{array}\right]\left[\begin{array}{l}
\mathbf{Y}^{\mathbf{t}} \\
\mathbf{Y}^{\mathbf{o}}
\end{array}\right]
$$

In our empirical application the 1394 "other" sectors are further partitioned into Agriculture, Energy and Resources, Other Manufactures, and Services according to the classification system in Appendix B.

We now introduce regional partitions to equation (3) so that we have Textiles and Clothing and All Other Sectors by region. We use 5 regions, Western Europe (1), BRIC (2), Other Europe (3), Other Affluent Countries (4), and Other Less Affluent Countries (5), each of which is a grouping of countries (defined in Table 1). Accordingly equation (3) becomes,

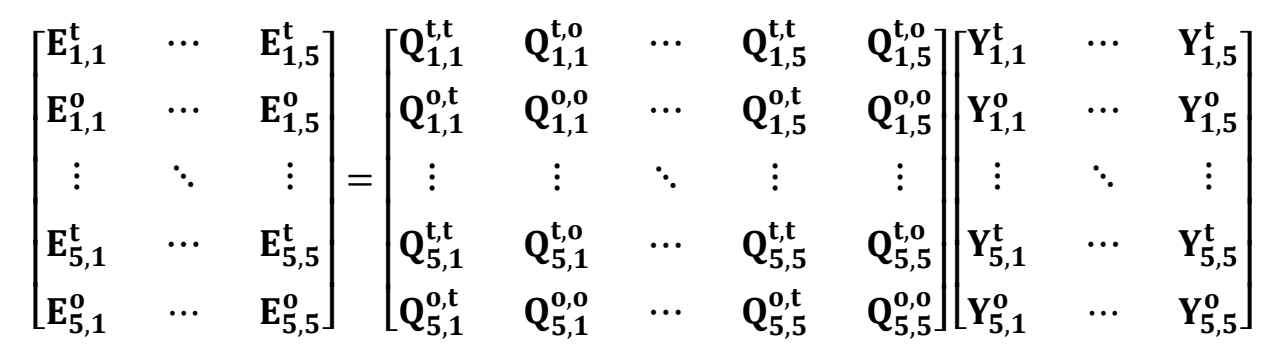

In equation (4) the first subscript is the region of production and the second is the region of consumption. So, $\mathbf{Y}_{5,1}^{\mathbf{t}}$ is consumption in Western Europe (subscript $\mathbf{1}$ ) of textile and clothing goods (superscript $\mathbf{t}$ ) produced in Other Less Affluent Countries (subscript 5). Similarly, $\mathbf{E}_{5,1}^{\mathbf{0}}$ is the impact produced in the non-textile sectors (superscript o) located in Other Less Affluent Countries (subscript 5) that was driven by consumption in Western Europe (subscript 1).

Table 1 Aggregation of countries into regions

Region

Western Europe (WEU)

Other Europe (OEU)

\section{Countries}

Austria, Belgium, Denmark, Finland, France, Germany, Greece, Ireland, Italy, Luxembourg, Netherlands, Portugal, Spain, Sweden, United Kingdom

BRIC Brazil, Russia, India, China 
Other Less

Affluent

Countries

Indonesia, Mexico, Rest of the World

(OLAC)

To isolate the textile and clothing value chains serving Western Europe we set the elements of all the consumption partitions other than those for Western European textiles and clothing consumption to zero. This leaves a modified $\mathbf{Y}$ matrix containing the WIOD final demand values for textiles and clothing in Western European countries and zeros everywhere else:

$$
\mathbf{Y}=\left[\begin{array}{cccc}
\mathbf{Y}_{1,1}^{\mathrm{t}} & \mathbf{0} & \cdots & \mathbf{0} \\
\mathbf{0} & \mathbf{0} & \cdots & \mathbf{0} \\
\mathbf{Y}_{2,1}^{\mathrm{t}} & \mathbf{0} & \cdots & \mathbf{0} \\
\mathbf{0} & \mathbf{0} & \cdots & \mathbf{0} \\
\mathbf{Y}_{3,1}^{\mathrm{t}} & \mathbf{0} & \cdots & \mathbf{0} \\
\mathbf{0} & \mathbf{0} & \cdots & \mathbf{0} \\
\mathbf{Y}_{4,1}^{\mathrm{t}} & \mathbf{0} & \cdots & \mathbf{0} \\
\mathbf{0} & \mathbf{0} & \cdots & \mathbf{0} \\
\mathbf{Y}_{5,1}^{\mathrm{t}} & \mathbf{0} & \cdots & \mathbf{0} \\
\mathbf{0} & \mathbf{0} & \cdots & \mathbf{0}
\end{array}\right](5)
$$

Equation (5) can be simplified by removing the columns that sum to zero,

$$
\mathbf{Y}=\left[\begin{array}{c}
\mathbf{Y}_{1,1}^{\mathrm{t}} \\
\mathbf{0} \\
\mathbf{Y}_{2,1}^{\mathrm{t}} \\
\mathbf{0} \\
\mathbf{Y}_{3,1}^{\mathrm{t}} \\
\mathbf{0} \\
\mathbf{Y}_{4,1}^{\mathrm{t}} \\
\mathbf{0} \\
\mathbf{Y}_{5,1}^{\mathrm{t}} \\
\mathbf{0}
\end{array}\right](6)
$$

We can then rewrite equation (4) with our modified $\mathbf{Y}$ to estimate the impacts that occurred in meeting that particular subset of global final demand: 


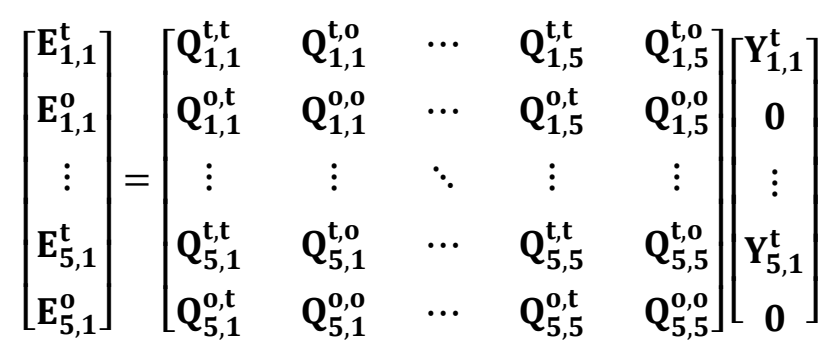

We apply equation (7) for each year, 1995-2009, and each indicator (see section 2.3). Finally, again for each year and indicator, we apply the following aggregations:

1. The production footprint: the sum of the impact vector,

$$
=\left[\begin{array}{llllllllll}
1 & 1 & 1 & 1 & 1 & 1 & 1 & 1 & 1 & 1
\end{array}\right]\left[\begin{array}{l}
E_{1,1}^{t} \\
E_{1,1}^{o} \\
E_{2,1}^{t} \\
E_{2,1}^{o} \\
E_{3,1}^{t} \\
E_{4,1}^{t} \\
E_{4,1}^{t} \\
E_{5,1}^{t} \\
E_{5,1}^{o}
\end{array}\right]
$$

2. Regional contributions to the production footprint: the sum of each regional partition of the impact vector,

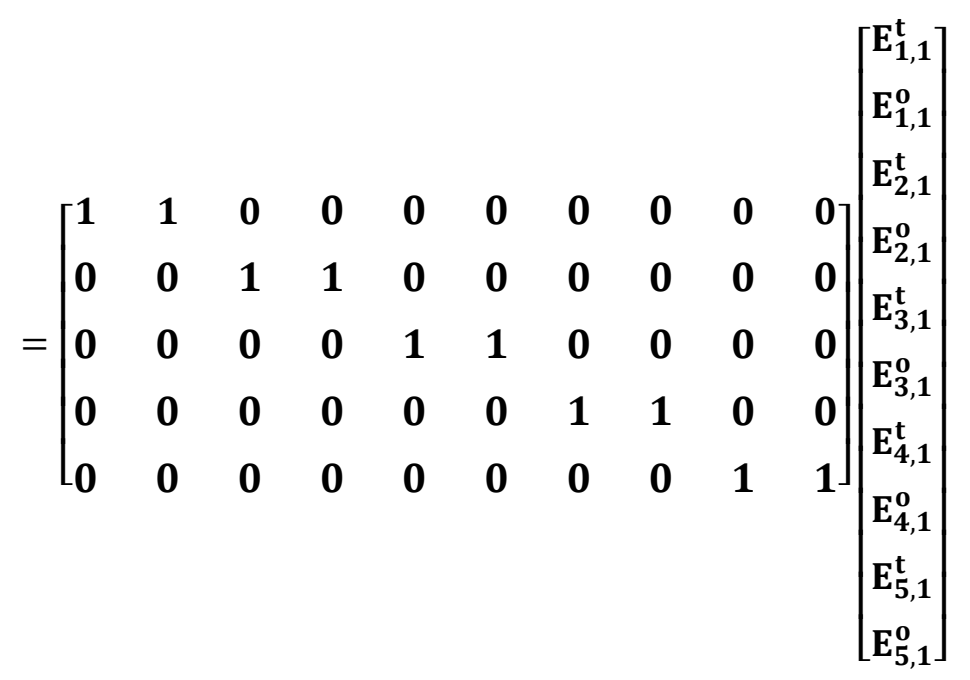

3. Sectoral contributions to the production footprint: the sum of each sector partition in the impact vector. Although in our application we use five sector partitions, the preceding equations only showed two sector partitions. In the case of two sector partitions the aggregation is, 


$$
\left[\begin{array}{llllllllll}
\mathbf{1} & \mathbf{0} & \mathbf{1} & \mathbf{0} & \mathbf{1} & \mathbf{0} & \mathbf{1} & \mathbf{0} & \mathbf{1} & \mathbf{0} \\
\mathbf{0} & \mathbf{1} & \mathbf{0} & \mathbf{1} & \mathbf{0} & \mathbf{1} & \mathbf{0} & \mathbf{1} & \mathbf{0} & \mathbf{1}
\end{array}\right]\left[\begin{array}{l}
\mathbf{E}_{1,1}^{\mathrm{t}} \\
\mathbf{E}_{1,1}^{\mathbf{0}} \\
\mathbf{E}_{2,1}^{\mathrm{t}} \\
\mathbf{E}_{2,1}^{\mathbf{0}} \\
\mathbf{E}_{3,1}^{\mathrm{t}} \\
\mathbf{E}_{3,1}^{\mathbf{0}} \\
\mathbf{E}_{4,1}^{\mathrm{t}} \\
\mathbf{E}_{4,1}^{\mathbf{0}} \\
\mathbf{E}_{5,1}^{\mathrm{t}} \\
\mathbf{E}_{5,1}^{\mathbf{0}}
\end{array}\right]
$$

\section{Sectoral contributions to the regional contributions to the production} footprint: the sum of one sector partition in each regional partition. This represents the least robust of our results (as it is the least aggregated), and as a result we do not present it for every indicator or every sector, but only where it provides additional substantive insights and where those insights can be readily explained by the existing literature. The aggregation for the Textiles and Clothing sector contributions to regional contributions to the production footprint given 2 sector partitions is,

$$
\left[\begin{array}{llllllllll}
\mathbf{1} & \mathbf{0} & \mathbf{0} & \mathbf{0} & \mathbf{0} & \mathbf{0} & \mathbf{0} & \mathbf{0} & \mathbf{0} & \mathbf{0} \\
\mathbf{0} & \mathbf{0} & \mathbf{1} & \mathbf{0} & \mathbf{0} & \mathbf{0} & \mathbf{0} & \mathbf{0} & \mathbf{0} & \mathbf{0} \\
\mathbf{0} & \mathbf{0} & \mathbf{0} & \mathbf{0} & \mathbf{1} & \mathbf{0} & \mathbf{0} & \mathbf{0} & \mathbf{0} & \mathbf{0} \\
\mathbf{0} & \mathbf{0} & \mathbf{0} & \mathbf{0} & \mathbf{0} & \mathbf{0} & \mathbf{1} & \mathbf{0} & \mathbf{0} & \mathbf{0} \\
\mathbf{0} & \mathbf{0} & \mathbf{0} & \mathbf{0} & \mathbf{0} & \mathbf{0} & \mathbf{0} & \mathbf{0} & \mathbf{1} & \mathbf{0}
\end{array}\right]\left[\begin{array}{l}
\mathbf{E}_{1,1}^{\mathrm{t}} \\
\mathbf{E}_{1,1}^{\mathbf{o}} \\
\mathbf{E}_{2,1}^{\mathrm{t}} \\
\mathbf{E}_{2,1}^{\mathbf{0}} \\
\mathbf{E}_{3,1}^{\mathrm{t}} \\
\mathbf{E}_{3,1}^{\mathbf{0}} \\
\mathbf{E}_{4,1}^{\mathrm{t}} \\
\mathbf{E}_{4,1}^{\mathbf{0}} \\
\mathbf{E}_{5,1}^{\mathrm{t}} \\
\mathbf{E}_{5,1}^{\mathbf{0}}
\end{array}\right]
$$

\subsection{Indicators}

To estimate socio-economic performance we follow Timmer et al. (2013a) in splitting gross value added into two parts, Labour Compensation, which we refer to as wages, and all other component parts which we refer to as profits (i.e. profits are gross value added minus wages). The profits production footprint represents returns to capital generated at every stage of the production process in producing the final good. Likewise, the wages production footprint represents the compensation of labour in producing the final good. Linked to the 
wages production footprint is the labour hours production footprint - the sum of labour hours worked in production of the final good. The labour hours production footprint complements the wages production footprint by providing a physical indication of labour use. By dividing the wages production footprint by the labour hours production footprint we estimate wage rates.

The carbon production footprint - the sum of the carbon dioxide emitted in production of the final good - is our environmental indicator. We do not assess non-carbon greenhouse gases because WIOD (see section 2.4) represents Agriculture as one sector and Agricultural subsectors are known to vary substantially in their non-carbon greenhouse gas intensities (Tukker and Dietzenbacher, 2013). It is also important to note that climate is only one environmental issue, however, carbon data is substantially more reliable than other environmental metrics and received special attention when constructing WIOD (Genty et al., 2012).

\subsection{Data}

All data are taken from the World Input-Output Database (WIOD). For a full description readers are directed to the relevant documentation (Dietzenbacher et al., 2013; Erumban et al., 2012; Genty et al., 2012; Timmer, 2012). In brief, WIOD provides harmonised multi-regional input-output tables covering 41 regions (40 countries and one rest of the world region) and corresponding socio-economic and environmental satellite accounts. We use WIOD rather than an alternative database (Giljum et al., 2008; Lenzen et al., 2013; Peters et al., 2011a; Tukker et al., 2013) for several reasons. First, WIOD provides detailed socio-economic statistics, including sector specific price indices and labour hours by sector. Second, it is built from publically available, official data, meaning that tracing the construction process of WIOD is easier than for other datasets, so that unusual results can be checked more readily. Additionally, WIOD improves upon a major source of uncertainty in multi-region input-output modelling; the import proportionality assumption. Applied to overcome a lack of detailed import data, the import proportionality assumption assumes that intermediate and final consumption share the same proportion of imports. WIOD improves upon this by differentiating between intermediate and final imports using detailed Comtrade data (Dietzenbacher et al., 2013). Finally, because WIOD is freely available ${ }^{2}$ our analysis is open to the broadest possible range of practitioners and researchers.

\footnotetext{
${ }^{2}$ Eora (Lenzen et al 2013) is also freely available to academic (university or grant-funded) work at degree-granting institutions.
} 
A drawback of WIOD is that it does not provide labour hours data or component breakdowns of gross value added for the Rest of the World (RoW) region. Therefore, the profit, wages and labour hours production footprints do not include RoW. Appendix A compares the gross value added production footprint including RoW with the gross value added production footprint excluding RoW. Results of this sense check suggest that although our wage and profit production footprints are underestimated, main trends are relatively unaffected. That said, we would expect production in the Rest of the World region (which includes, for example, Cambodia and Bangladesh) to be Labour rather than capital intensive. Hence we would expect most of the value added in this region to be wages. This implies that not including contributions from RoW had the biggest effect on the wages production footprint. A similar assessment was not possible for the labour hours production footprint, but it is likely that excluding labour intensive low-wage economies of RoW also underestimates the labour hours production footprint.

The gross value added and wages data in WIOD's socio-economic accounts are provided in nominal national currencies. To examine changes overtime we use the sector level price indices for value added from WIOD to deflate wage and profit data to 1995 prices. In order to compare regions we convert national currencies to US dollars. Conversion of multiple national currencies to a common currency can be done with either Purchasing Power Parity (PPP) conversion factors or Market Exchange Rates (MER). MERs reflect price differences in internationally traded goods, while PPP conversion factors reflect differences in both internationally traded and domestic goods (such as haircuts). Consequently, PPPs control for differences in the purchasing power of different national currencies, while MERs do not. This means that MERs underestimate the local value of profits and wages in developing countries (but typically have little effect on developed countries) (Nordhaus, 2007; Ortiz and Cummins, 2011). However, estimating detailed PPP timeseries is a complex process, with substantial conceptual difficulties, while MER timeseries are much easier to estimate and therefore more widely available (Callen, 2007; Deaton and Heston, 2010; Ortiz and Cummins, 2011). Therefore, we use MER to convert wages and profits in national currencies to US dollars, acknowledging that this increases the inequalities that we find relative to using PPP. Nevertheless, our results are useful for identifying potential hotspots, trends, and areas for further detailed investigation. As a further mitigating measure, we apply a MER to PPP adjustment factor in some of our detailed regional investigation. This allows us to investigate the difference that PPP might make to our results. Specifically, MER is thought to underestimate the true value of income in developing countries by a factor of around 3 (Callen, 2007; Nordhaus, 2007) and we multiply our results (obtained using MER) for BRIC by a PPP adjustment factor of 3 to see if observed inequalities still hold. 


\section{RESULTS}

\subsection{Trends in Production Footprints}

Figure 2 shows trends in Western European consumption deflated to 1995 USD alongside the Western European textiles and clothing production footprints for carbon, labour hours, wages, and profit. They are the sum of the impacts of every stage of production. Sections 3.2 and 3.3 show regional and sectoral contributions to the Wetsern European textiles and clothing production footprints respectively.

In line with levels of real Western European textiles and clothing consumption, all production footprints fell after 1995. However, while the labour hours production footprint and carbon production footprint rose again after 1997 the wages and profit production footprints continued to fall until $2001^{3}$. After 2002 , there is a pronounced upward trend in all indicators driven by the corresponding increase in levels of consumption. The profit and wages production footprints continue to follow the consumption trend closely, rising with consumption expenditure but never quite recovering to 1995 levels.

All production footprints decrease again at the end of the time series. The 2008 recession caused consumption to fall again, explaining some of the fall in the production footprints. However, falls in the carbon and labour hours production footprints prior to 2008 cannot be explained by recession or falling consumption. Rather, pre-2008 reductions in the labour hours production footprint and carbon production footprint may indicate production processes that have become more carbon and labour efficient with respect to consumption. This is what we would expect - capitalist economies are good at efficiency. However, two things should be noted here. First, between 2002 and 2007 carbon emissions rose slightly as efficiency gains were outstripped by the rapid growth in consumption and two of the biggest falls in the carbon production footprint occurred between 1995-1997 and 2008-2009, times when levels of consumption also fell. This is in line with other work showing that rising consumption is an important driver of emission profiles (Brizga et al., 2014; Peters et al., 2007). Second, whilst improved efficiency seems a possible explanation for the decoupling of the carbon production footprint and levels of consumption after 2007 this is less plausible for the sharp reduction in the labour hours production footprint. Rather, we hypothesise that

\footnotetext{
${ }^{3}$ Note that wage and profit production footprints do not include the RoW region (as detailed in
} section 2.4). However, the aggregate gross value added production footprint (which does include RoW data) does not show substantial deviation from the wage and profit production footprint trends (see appendix A). 
at least some of this sharp fall is indicative of the rising importance of countries for which we do not have labour hours data (section 2.4).

Figure 2 also shows that the wage rate (the cost of labour per hour) in producing textiles and clothing goods for Western European consumers fell between 1996 and 2006 and has not quite recovered by 2009. This is likely the result of increased use of labour in lower wage nations and the reduced use of labour in more economically developed nations (Dunford, 2004), something considered further in section 3.2. We should, however, be aware that the use of MERs is likely to overstate the fall in wage rate considered from the perspective of workers. That is, if the falling wage rate is due to increased use of workers in developing countries, the lower wages have increased purchasing power in those countries, and so the effects of any fall are lessened.

In Figure 2 we see that the profit production footprint recovered more rapidly and to a greater extent than the wages production footprint, particularly at the end of the time series. This potentially indicates profit seeking behaviour with low wage labour subsidising profit margins. Although this is consistent with the idea that manufacturing sectors in developing countries use cheap labour to maintain higher profit margins while out-competing their developed country counterparts on cost, this has a relatively high level of uncertainty due to the exclusion of RoW data for these production footprints.

Figure 3 expands on the relationship between the wages and profit production footprints by showing their absolute values rather than their normalised trends. In Figure 3 we see that although the wage production footprint fell at a greater rate than profits, it was consistently a bigger cost component. This raises questions about the ability of firms to absorb wage increases, and supports the argument that as wages increase in current manufacturing hubs manufacturing will move elsewhere.

In summary, there has been a mixed picture for sustainability. Changes in production may have had some success in decoupling the Western European textiles and clothing carbon production footprint from levels of consumption. However, the wages production footprint was highest in 1995, and the time series is dominated by a decline in real wages. In order to form a clearer picture of the sustainability of Western European textiles and clothing consumption we now explore the geographical spread of the production footprints.

\subsection{Regional Contributions to Production Footprints}

Figure 4 shows the regional breakdown of the Western European textiles and clothing consumption production footprints for labour hours; wages; profit; and carbon. That 
is, each panel in Figure 4 shows how much of each production footprint occurred in each region. Western Europe shows declining contributions to all these production footprints. This is in line with reported shifts away from developed countries in textiles and clothing and other manufacturing production (Dicken, 2011; Dunford, 2004; Los et al., 2014) and confirms that the production of textiles and clothing goods for Western Europe increasingly takes place outside of Western Europe. 


\subsubsection{Labour Hours and Wages}

The regional breakdown of the labour hours production footprint (Figure 4) reveals that BRIC has supplied a majority of labour through the entire period, confirming expectations (Kaplinsky and Morris, 2006). Likewise, we see rapid growth in BRIC labour use after 2001 which is likely due to the $2^{\text {nd }}$ stage phasing out of quotas on world trade in textiles and clothing (Adhikari and Yamamoto, 2007; Spinanger, 1999). This is problematic as both China and India are known to have particularly poor working conditions and restricted rights for workers (International Trade Union Confederation, 2014; Song, 2014).

In contrast to the labour hours production footprint, the regional breakdown of the wages production footprint (Figure 4) shows that Western Europe dominated the wages production footprint throughout the time series while, despite being the biggest contributor to the labour hours production footprint, BRIC is still marginal in terms of the wages production footprint. These discrepancies translate into the effective real wage rates shown in Figure 5. Figure 5 also shows that because the difference between the wage rates is so large, it is unlikely to be substantially effected by use of PPP rather than MER. 
The substantial inequities between wage rates in Western Europe and BRIC supports the suggestion that Western European production is in the highly skilled, high value portions of the global value chains, such as design and research and development (Nordås, 2004; Sørensen, 2008). Likewise, it suggests that the jobs created in BRIC by Western European textiles and clothing consumption are in the low skilled, low value portions of the global value chains.

On the other hand, real BRIC wage rates doubled between 1995 (wage rate $=0.31$ 1995 USD per hour) and 2009 (wage rate $=0.621995$ USD per hour). This suggests that the material quality of life for BRIC workers has been improved by globalisation in the textiles and clothing value chains that serve Western Europe. Moreover, Gereffi and Memedovic (2003), argue that countries can 'move up' value chains by capturing higher value activities. The rise in BRIC wage rates suggests more skilled, higher value work is being undertaken in BRIC. This supports the long standing contention that regions outside Europe, not only have "low labour input costs to be exploited, but also an increasing availability of highly skilled labour"(Giuli, 1997 P.2 ) and that firms are beginning to capitalise on this (Tewari, 2006).

Qualifying these results is that WIOD does not have Labour data for the RoW region which is included in the Other Less Affluent Countries region (Table 1). The likely effect of this is that our estimates are conservative indicators for low wage labour use (Appendix A) others have shown that the value chains supplying affluent nations tend to rely on high quantities of overseas cheap labour (Alsamawi et al., 2014).

\subsubsection{Profits}

Figure 4 shows that after 2002 BRIC began to generate a much greater share of the profit production footprint, in 2009 almost matching the Western European contribution (and likely surpassing it if a PPP rather than MER measure was used). As with the growing wage rates this suggests BRIC is moving up the value chain. An increase in BRIC contributions to the profit production footprint may also indicate a move toward more capital intensive parts of the global value chains serving Western European Textiles and Clothing consumers, as the profit production footprint represents returns on capital. Provided this capital income remains in BRIC and does not subsequently flow abroad, this would a positive development for BRIC. Nonetheless, it is worth noting that the BRICs contributions to the profit production footprint increased substantially faster than its contribution to the wages production footprint. Consequently, the graph may provide further evidence of profit seeking behaviour - 
especially as the contributions to the profit production footprint are much more likely than the contributions to the wages production footprint to leave BRIC through complex ownership and accounting structures.

\subsubsection{Carbon}

Figure 4 shows that contributions from BRIC and the Other Less Affluent Countries (OLAC) became increasingly important to the Western European textiles and clothing carbon production footprint. This is in line with other studies finding that offshore emissions constitute increasingly bigger portions of the carbon footprints of affluent nations (Peters et al., 2011b; Wiedmann et al., 2010). There also appears to be a link between the Western European textiles and clothing carbon and labour hours production footprints as both follow similar regional patterns, with BRIC contributions to both spiking after 2002 (about the time of the third stage removal of MFA quotas (Spinanger, 1999)). This suggests carbon and labour intensive production relocated to similar geographical locations.

As the contributions to the carbon production footprint from Western Europe, Other Europe and the Other Affluent Countries all declined after 1997, the growth in the overall Western European textiles and clothing carbon production footprint between 1997 and 2000 (Figure 2) was the result of the growth in carbon emissions from BRIC and OLAC during this period. Moreover, in Figure 2 we see that Western European consumption of textiles and clothing goods fell between 1997 and 2000. Therefore, increases in contributions to the carbon production footprint from BRIC and OLAC between 1997 and 2000 were likely due to the more carbon intensive nature of BRIC and OLAC production systems.

After 2002 growth in BRIC contributions to the carbon production footprint grew rapidly, but there was only moderate growth in the overall carbon production footprint (Figure 2). This is because Western European and OLAC contributions to the carbon production footprint begin to decline shortly after 2002, suggesting that a large portion of the growth in BRIC contributions to the carbon production footprint after 2002 was a displacement of carbon emissions from Western Europe and OLAC. The overall growth in the carbon production footprint between 2002 and 2007 (which is relatively small) can be attributed to the increase in Western European textiles and clothing demand after 2002.

It is also worth noting that this demand grew much more rapidly than the carbon production footprint - implying a decrease in the carbon intensity of BRIC production relative to final demand. On the other hand, until 2007, levels of demand remained below 1995 levels and so the carbon intensity of production in the textiles and clothing value chains 
serving Western Europe remained higher than in 1995. From this we infer that despite its decreasing trend, the carbon intensity of BRIC production between 2002 and 2007 was still greater than the carbon intensity of Western European production in 1995.

\subsection{Sectoral Contributions to Production Footprints}

Figure 6 shows the sectoral contributions to the Western European textiles and clothing production footprints for carbon; labour hours; profit; and wages. The Textiles and Clothing sector is the biggest contributor to the labour hours, wages and profit production footprints and the second biggest contributor to the carbon production footprint after the Energy and Resources Sector. In all cases, by 2009, the contributions of the Textiles and Clothing sector had fallen relative to 1995 , albeit only slightly in the labour hours production footprint. 


\subsubsection{Labour Hours and Wages}

The biggest contribution to the labour hours production footprint was the Textiles and Clothing sector (Figure 6). This can be explained by the highly labour intensive nature of clothing production; because cloth is soft and flexible, mechanising the process has proved difficult in clothing production (though not in textiles production) (Dicken, 2011; OECD, 2004). The wages production footprint is also dominated by the Textiles and Clothing sector. Figure 7 shows that this is the result of the high wages paid to Textiles and Clothing sector workers in Western Europe. Figure 6 should be interpreted with care as it represents the highest level of uncertainty of our analysis. However, it corresponds to expectations in the literature regarding the geographical distribution of work in the Textiles and Clothing sector (design and other skilled activities in affluent nations and low skilled manual labour in developing nations (Nordås, 2004)). Therefore we feel confident in interpreting Figure 6 as further evidence of reliance of Western European Textiles and Clothing retailers and consumers on low wage labour in BRIC.

A similar picture emerges for the Agricultural industry. Unlike clothing production, mechanisation of, for example, cotton production is possible and in the USA has greatly reduced labour requirements (Rivoli, 2006). However, the regional breakdown of labour hours production footprint (Figure 5) shows that the BRIC labour contribution shows very similar patterns to the Textiles and Clothing and Agricultural sectors contributions to the labour hours production footprint (Figure 6), suggesting that most of the increase in the labour hours was within the Textiles and Clothing and Agricultural Sectors in BRIC countries. This is supported by the fact that China, Brazil, and India were consistently among the top 10 global cotton producers between 1995 and 2009 (FAOSTAT, 2014) and rely on substantial quantities of labour-intensive hand harvesting (Chaudry, 2004). However, there is one important difference between the Textiles and Clothing and Agricultural sectors: the latter contributes much less than the former to the wage production footprint, despite similar contributions to the labour hours production footprint. This may be because there are very few high value activities in Agricultural sector, whereas the Textiles and Clothing sector has design and branding focused jobs (EMCC, 2008). This analysis of the Agriculture and Textiles and Clothing sectors provides evidence that price pressures are being passed down value chains - potentially suppressing wages. 


\subsubsection{Profits}

The sectoral breakdown of the Western European textiles and clothing profit production footprint (Figure 6) mirrors that of the wage production footprint with the biggest profits being seen in the Textiles and Clothing sector itself and Agriculture contributing proportionally much less to the profit production footprint than to the labour hours production footprint. The suggested explanation for this is the same as in section 3.3.1 - the Textiles and Clothing sector contains both high and low value-adding production tasks, while agriculture does not. An additional insight from the sector breakdown of the profit production footprint is that the contributions from the Services and Other Manufactures sectors saw a marked increase after 2002 whereas the wage footprints in these sectors rose much more modestly. This again suggests growth in profits at the expense of wages.

\subsubsection{Carbon}

Section 3.2.3 argued that increases in the carbon production footprint between 1997 and 2001 were likely due to movement of manufacturing out of Western Europe and into BRIC and OLAC. Figure 6 shows that contributions to the carbon footprint from the Energy and Resources sector follows a similar trend as contributions from BRIC and OLAC. This suggests that the reason for the growth in the carbon production footprint at this time was due to a shift amongst manufacturers to regions with more carbon intensive Energy and Resources sectors.

Figure 8 breaks down the contributions of the Energy and Resources sector to the Western European Textiles and Clothing carbon production footprint, showing the BRIC Energy and Resources sector to be the biggest contributor. As with Figure 6 this represents a high level of uncertainty. Nonetheless, the pattern is in line with the wider literature. For example, Andrew and Peters (2013) report that the Chinese Electricity sector was the biggest contributor to the UK, French and Norwegian Clothing Greenhouse Gas production footprints for 2007 while the Carbon Trust (2011) reported that the Chinese Electricity Sector was the biggest contributor to the UK's clothing carbon production footprint for 2004 . Therefore we conclude that the biggest source of carbon in the Western European textiles and clothing carbon production footprint was the BRIC Energy and Resources sector. Further, we conclude that the carbon intensity of the background energy system has been of considerable importance in determining the Western European textiles and clothing carbon production footprint. 


\section{Discussion - SUSTAINABLE FUTURES?}

Several key findings emerge from our analysis. First, Western European consumption of textiles and clothing goods between 1995 and 2009 relied on large quantities of low paid labour principally in the Textiles and Clothing, and Agricultural sectors in BRIC, whilst more highly paid jobs were found in Western Europe. Alsamawi et al., (2014) characterise this type of relationship as a "master" and "servant" relationship, the low paid servant nations supporting the affluent lifestyles of the wealthy master nations. This type of inequity does not sit easily with visions of a sustainable future where intra-generational equity is key (Brundtland, 1987; Haughton, 1999; Jackson, 2011).

Achieving intra-generational equity requires an increase in the income of the global poor sufficient to both meet their material needs and to partake in society. Our analysis does provide evidence that BRIC workers benefitted from removal of restrictions on international trade - wages rose as production moved into BRIC. However, the remaining large differences in wage rates suggest that this development path is likely to take a long time to reach a more equitable situation, especially if, as we suggest, production is now moving out of BRIC and into lower wage nations.

One way to speed up progress toward equity and to better enable BRIC workers to flourish, is for Western European brands to enforce payment of higher wages by their suppliers. This is a strategy that curries favour with third sector groups. For example, the Asia Living Wage Floor Alliance is a group of unions and labour activists from across Asia whom advocate payment of a living wage to garment workers ${ }^{4}$. Moreover, McMullen et al (2014) report that New Look, the British high street chain, is already paying a living wage to some of its workers in China. However, how New Look finance this is unclear. Also unclear is the extent to which payment of a living wage affects production cost. Beyond studies examining the consumer price effects of increases in the minimum wage in developed nations (Aaronson, 2001; O'Brien-Strain and MaCurdy, 2000) we find very limited consideration of this in the literature. Our analysis here showed that labour costs already dominate profits, but also that per unit labour costs fell substantially. Therefore we flag this as an interesting area for future research.

It is also worth noting that the Asia Living Floor Wage Alliance and the McMullen report focus on improving prospects of workers in clothing factories. By highlighting the substantial contributions to the Western European Textiles and Clothing labour hours production footprint of Agriculture, our analysis shows that a focus on garment workers alone

\footnotetext{
${ }^{4}$ http://www.cleanclothes.org/livingwage/who-are-the-asia-floor-wage-alliance
} 
will not be sufficient to remove dependency on low wage labour. For that, wage increases must also be made in other sectors, in particular Agriculture.

Next, we found that the biggest contributor to the Western European textiles and clothing carbon production footprint was the Energy and Resources sector in BRIC, and that movement of manufacturing to BRIC represented both displacement and growth in global emissions at different points in time. This indicates the importance of decarbonising economies, especially those of the nations where industry is expected to relocate. Therefore sustainable textiles and clothing consumption relies on energy companies and governments to ensure a sustainable future for manufacturing by investing in low carbon energy infrastructures.

Third, for substantial portions of the time series, efficiency gains in the Western European textiles and clothing carbon production footprint, were outstripped by rising levels of consumption. Consequently, our results suggest large scale reductions in carbon emissions from Western European textiles and clothing would be facilitated by reductions in levels of consumption. Therefore, Western European retailers may need to rethink their business models, and consumers their consumption choices, in order to absolutely reduce per capita consumption levels. This recommendation is in line with arguments that achieving a sustainable society will require substantial lifestyle changes in affluent nations away from consumerist values (Duchin and Lange, 1994; Jackson, 2009).

One way to bring together a reduction in consumption in affluent nations and increased wages in poorer nations is the "better rather than more" strategy (Clift et al., 2013; Girod and De Haan, 2010) which advocates a reduction in the volume of consumption by purchasing "better" products at a higher price. The difficulty with such a strategy lies in defining what it means for a product to be "better". One interpretation of "better" in this context is "more equitable". That is, a better product can be understood as one with a more equitable value chain - fairer wages and stronger rights for workers in all sectors and countries. Following this understanding the better rather more strategy by definition leads to increased income for low wage workers in the value chain. Moreover, it has been argued elsewhere that low costs of consumer goods encourages short lifespans for those goods (Cox et al., 2013). Wage increases, better working conditions and improved rights would all be expected to increase production costs. Depending on the magnitude of these costs, passing them through to the final consumer could be enough to begin tipping consumer preferences away from high volume consumption thus reducing carbon emissions and achieving greater socio-economic and environmental sustainability for Western European textiles and clothing consumption. 


\section{CONCLUSIONS}

In this study we developed a sub-system global multi-regional input-output framework and used it to estimate trends in the socio-economic and carbon impacts of Western European consumption of textiles and clothing goods between 1995 and 2009. We showed that production moved out of Western Europe, predominantly into BRIC and we found a substantial fall in the wage rate for producing textiles and clothing goods for Western European consumers. The reduced wage rate was the result of large increases in low wage labor in the BRIC Agricultural, and Textiles and Clothing sectors. BRIC workers in the value chains that serve Western European textiles and clothing consumers earn around $3 \%$ of the hourly rate of their Western European counterparts (at market exchange rates) - a substantial inequity. However, wage rates in BRIC grew between 1995 and 2009, and profits are increasingly being generated within BRIC. We hypothesise that this is the result of BRIC moving towards producing higher value goods as production of the very cheap low value added goods moves out of BRIC and into poorer countries - many of which we do not have data for.

Initially, movement of production from Western Europe to BRIC increased the carbon intensity of the production of textiles and clothing goods for Western Europe, cancelling out the effect of falling demand. From 2002 onwards, BRIC production became more carbon efficient but this was outpaced by increased demand and so the carbon production footprint in 2007 was approximately the same as it had been in 1995. However, after 2007 carbon emissions from the BRIC Energy and Resources sector fell and combined with reduced consumption (due to recession) in 2008 and 2009, this was enough to give a reduction in the 2009 Western European textiles and clothing carbon footprint relative to 1995. While this overall trend in the carbon production footprint is not discouraging, to stop runaway climate change more ambitious and robust reductions will be needed (IPCC, 2014).

In summary, our study presents a mixed picture for sustainability. The empirical evidence appears to support previous arguments that Western European textiles and clothing retail models are reliant on cheap labour and inequities. However, we cannot advocate localisation of production on social grounds as we have shown that globalisation appears to have substantially increased wages for BRIC workers. Our results also support the idea that high volume business models hamper otherwise successful attempts to reduce carbon emissions. In the light of these findings, we argued that increasing wages in BRIC (and other low wage countries) would act to improve socio-economic sustainability. 
Additionally, by passing on the increased cost of conditions for BRIC workers to Western European consumers, improvements in environmental sustainability could also be achieved.

\section{ACKNOWLEDGEMENTS}

This work was jointly supported by the UK's Economic and Social Research Council and Natural Environment Research Council, grant number ES/J500148/1. We would like to thank Professor Karen Turner and two anonymous reviewers for their helpful comments and suggestions.

\section{REFERENCES}

Aaronson, D., 2001. Price Pass-Through and the Minimum Wage. Review of Economics and Statistics 83, 158-169

Acquaye, A., Duffy, A., Basu, B., 2011. Stochastic hybrid embodied CO2-eq analysis: An application to the Irish apartment building sector. Energy and Buildings 43, 1295-1303.

Acquaye, A., Genovese, A., Barrett, J., Koh, L., 2014. Benchmarking Carbon Emissions Performance in Supply Chains. Supply Chain Management: An International Journal 19, 306321.

Adhikari, R., Yamamoto, Y., 2007. The textile and clothing Industry: Adjusting to the postquota world, Industrial Development for the 21st Century: Sustainable Development Perspectives. United Nations, Department of Economic and Social Affairs, New York, p. 432.

Allwood, J.M., Laursen, S.E., Rodriguez, C.M., Brocken, N.M.P., 2006. Well dressed? The present and future sustainability of clothing and textiles in the United Kingdom. Cambridge, UK, University of Cambridge Institute for Manufacturing.

Alsamawi, A., Murray, J., Lenzen, M., 2014. The Employment Footprints of Nations. Journal of Industrial Ecology 18, 59-70.

Andrew, R., Peters, G., 2013. Optimal Carbon Policy for Supply Chain Analysis.

Andrew, R., Peters, G., Lennox, J., 2009. Approximation And Regional Aggregation In Multi-Regional Input-Output Analysis For National Carbon Footprint Accounting. Economic Systems Research 21, 311-335.

Bradley, P., Druckman, A., Jackson, T., 2013. The development of commercial local area resource and emissions modelling - navigating towards new perspectives and applications. Journal of Cleaner Production 42, 241-253.

Brizga, J., Feng, K., Hubacek, K., 2014. Drivers of greenhouse gas emissions in the Baltic States: A structural decomposition analysis. Ecological Economics 98, 22-28. 
Brundtland, G.H., 1987. World commission on environment and development. Our common future, 8-9.

Callen, T., 2007. PPP Versus the Market: Which Weight Matters? Finance \& Development 44, 1-4.

Carbon Trust, 2011. International Carbon Flows: Clothing.

Chaudry, R., 2004. Harvesting and Ginning Cotton in the World. International Cotton Advisory Committee, Washington, DC.

Chen, H.-L., Burns, L.D., 2006. Environmental Analysis of Textile Products. Clothing and Textiles Research Journal 24, 248-261.

Claudio, L., 2007. Waste Couture: Environmental Impact of the Clothing Industry. Environmental Health Perspectives 115, A449-A454.

Clift, R., Sim, S., Sinclair, P., 2013. Sustainable consumption and production: quality, luxury and supply chain equity, in: Jawahir, I., Sikdar, S., Huang, Y. (Eds.), Treatise on Sustainability Science and Engineering. Springer.

Cox, J., Griffith, S., Giorgi, S., King, G., 2013. Consumer understanding of product lifetimes. Resources, Conservation and Recycling 79, 21-29.

Davis, S.J., Peters, G.P., Caldeira, K., 2011. The supply chain of CO2 emissions. Proceedings of the National Academy of Sciences of the United States of America 108, 18554.

Deaton, A., Heston, A., 2010. Understanding PPPs and PPP-based National Accounts. American Economic Journal: Macroeconomics 2, 1-35.

Dicken, P., 2011. 'Fabric-ating Fashion': The Clothing Industries, in: Dicken, P. (Ed.), Global Shift: Mapping the Changing Contours of the World Economy, 6th ed. Sage Publications, pp. 302-330.

Dietzenbacher, E., Los, B., Stehrer, R., Timmer, M., G, d.V., 2013. The Construction of World Input-Output Tables in the WIOD Project Economic Systems Research 25.

Druckman, A., Bradley, P., Papathanasopoulou, E., Jackson, T., . 2008. Measuring progress towards carbon reduction in the UK. Ecological Economics 66, 594-604.

Druckman, A., Jackson, T., 2009. The carbon footprint of UK households 1990-2004: A socio- economically disaggregated, quasi- multi- regional input- output model. Ecological Economics 68, 2066-2077.

Duchin, F., Lange, G.-M., 1994. The future of the environment: ecological economics and technological change.

Dunford, M., 2004. The Changing Profile and Map of the EU Textile and Clothing Industry, in: Faust, M., Voskamp, U., Wittke, V. (Eds.), European Industrial Restructuring in a Global Economy: Fragmentation and Relocation of Value Chains. SOFI.

EMCC, 2008. Textiles and clothing sector: Herning-Ikast-Brande cluster, Denmark. 
Erumban, A., Gouma, R., De Vries, G.J., De Vries, K., Timmer, M.P., 2012. WIOD SocioEconomic Accounts (SEA): Sources and Methods.

FAOSTAT, 2014. Cotton production statistics by country. Food And Agriculture Organization Of The United Nations Statistics Division.

Feenstra, R., Hanson, G., 1996. Globalization, Outsourcing, and Wage Inequality, NBER Working Paper 5424.

Francois, J., Manchin, M., H, N., Spinanger, D., 2007. Impacts of Textiles and Clothing Sectors Liberalisation on Prices, Economic Analysis in Support of Bilateral and Multilateral Trade Negotiations.

Genty, A., Arto, I., Neuwahl, F., 2012. Final Database of Environmental Satellite Accounts: Technical Report on Their Compilation. WIOD.

Gereffi, G., Memedovic, O., 2003. The Global Apparel Value Chain: What Prospects for Upgrading by Developing Countries? United Nations Industrial Development Organization, Vienna, Austria.

Giljum, S., Lutz, C., Jungnitz, A., 2008. The Global Resource Accounting Model (GRAM) A methodological concept paper.

Girod, B., De Haan, P., 2010. More or Better? A Model for Changes in Household Greenhouse Gas Emissions due to Higher Income. Journal of Industrial Ecology 14, 31-49.

Giuli, M., 1997. The competitiveness of the European textile industry, Research Papers in International Business, No.2-97. Centre for International Business Studies, South Bank University, London.

Haughton, G., 1999. Environmental Justice and the Sustainable City. Journal of Planning Education and Research 18, 233-243.

International Trade Union Confederation, 2014. ITUC Global Rights Index: The world's worst countries for workers.

IPCC, 2014. CLIMATE CHANGE 2014 Synthesis Report, Intergovernmental Panel on Climate Change.

Jackson, T., 2009. Prosperity without growth : economics for a finite planet. London : Earthscan, London.

Jackson, T., 2011. Societal transformations for a sustainable economy. Natural Resources Forum 35, 155-164.

Kanemoto, K., Moran, D., Lenzen, M., Geschke, A., 2014. International trade undermines national emission reduction targets: New evidence from air pollution. Global Environmental Change 24, 52-59.

Kaplinsky, R., Morris, M., 2006. Dangling by a Thread: How Sharp are Chinese Scissors? 
Lenzen, M., 2011. Aggregation Versus Disaggregation In Input-Output Analysis Of The Environment. Economic Systems Research 23, 73-89.

Lenzen, M., Moran, D., Kanemoto, K., Foran, B., Lobefaro, L., Geschke, A., 2012. International trade drives biodiversity threats in developing nations. Nature 486, 109-112.

Lenzen, M., Moran, D., Kanemoto, K., Geschke, A., 2013. Building Eora: A Global MultiRegion Input-Output Database at High Country and Sector Resolution. Economic Systems Research 25, 20-49.

Lenzen, M., Wood, R., Wiedmann, T., 2010. Uncertainty Analysis for Multiregion InputOutput Models - A Case Study of the UK's Carbon Footprint. Economic Systems Research 22, 43-63.

Los, B., Timmer, M.P., de Vries, G.J., 2014. How Global Are Global Value Chains? A New Approach To Measure International Fragmentation. Journal of Regional Science, 1, 66-92.

McMullen, A., Luginbühl, C., Nolan, K., Crabbé, C., Ajaltouni, N., 2014. Tailored Wages.

Miller, R., Blair, D., 2009. Input output analysis, foundations and extensions. Prentice-Hall, New Jersey.

Moran, D.D., Lenzen, M., Kanemoto, K., Geschke, A., 2013. Does ecologically unequal exchange occur? Ecological Economics 89, 177-186.

Morris, M., Barnes, J., 2008. Globalization, the Changed Global Dynamics of the Clothing and Textile Supply Chains and the Impact on Sub-Sahran Africa, Research and Statistics Branch Working Paper 10/2008. United Nations Industrial Development Organization, Vienna.

Nordås, H.K., 2004. The Global Textile and Clothing Industry post the Agreement on Textiles and Clothing, Discussion Paper No.5. World Trade Organization, Geneva, Switzerland.

Nordhaus, W., 2007. Alternative measures of output in global economic-environmental models: Purchasing power parity or market exchange rates? Energy Economics 29, 349-372.

O'Brien-Strain, M., MaCurdy, T., 2000. Increasing the Minimum Wage: California's Winners and Losers, PPIC.

OECD, 2004. Policy Brief, A New World Map in Textiles and Clothing: adjusting to change. OECD, Paris.

Ortiz, I., Cummins, M., 2011. Global Inequality: Beyond the Bottom Billion - A Rapid Review of Income Distribution in 141 Countries.

Peters, G., Andrew, R., Lennox, J., 2011a. Constructing an environmentally extended multiregional input-output table using the GTAP database. Economic Systems Research 23, 131152. 
Peters, G., Minx, J.C., Weber, C.L., Edenhofer, O., 2011b. Growth in emission transfers via international trade from 1990 to 2008. Proceedings of the National Academy of Sciences of the United States of America 108, 8903.

Peters, G.P., Weber, C.L., Guan, D., Hubacek, K., 2007. China's Growing CO2 Emissions A Race between Increasing Consumption and Efficiency Gains. Environmental Science \& Technology 41, 5939-5944.

Piaggio, M., VPadilla, E, 2015. The materiality of the immaterial: Service sectors and CO2 emissions in Uruguay. Ecological Economics 110, 1-10.

Rivoli, P., 2006. The Travels of a T-Shirt in the Global Economy. Wiley, USA.

Schnabl, H., 1995. The Subsystem-MFA: A Qualitative Method for Analyzing National Innovation Systems-The Case of Germany. Economic Systems Research 7.

Schor, J., 2005. Prices and quantities: Unsustainable consumption and the global economy. Ecological Economics 5, 309-320.

Simas, M., Golsteijn, L., Huijbregts, M., Wood, R., Hertwich, E., 2014a. The "Bad Labor" Footprint: Quantifying the Social Impacts of Globalization. Sustainability 6, 7514-7540.

Simas, M., Wood, R., Hertwich, E., 2014b. Labor Embodied in Trade. Journal of Industrial Ecology.

Song, Y., 2014. What should economists know about the current Chinese hukou system? China Economic Review 29, 200-212.

Sørensen, S.Y., 2008. EU textiles and clothing sector: Location decisions. European Foundation for the Improvement of Living and Working Conditions, Dublin.

Spinanger, D., 1999. Textiles Beyond the MFA Phase-Out. World Economy 22, 455-476.

Taplin, I., 2006. Restructuring and reconfiguration: The EU textile and clothing industry adapts to change. European Business Review 18, 172 - 186.

Taplin, I., 2014. Who is to blame? A re-examination of Fast Fashion after the 2013 factory disaster in Bangladesh. critical perspectives on international business 10.

Tewari, M., 2006. Adjustment in India's textile and apparel industry: reworking historical legacies in a post-MFA world. Environment and Planning A 38, 2325.

Timmer, M.P., 2012. The World Input-Output Database (WIOD): Contents, Sources and Methods, WIOD Working Paper Number 10.

Timmer, M.P., Erumban, A., Los, B., Stehrer, R., de Vries, G.J., 2013a. Slicing Up Global Value Chains.

Timmer, M.P., Los, B., Stehrer, R., de Vries, G.J., 2013b. Fragmentation, incomes and jobs: an analysis of European competitiveness. Economic Policy 28, 613-661. 
Tokatli, N., Kizilgun, O., Cho, J., 2011. The Clothing Industry in Istanbul in the Era of Globalisation and Fast Fashion. Urban Studies 48, 1201-1215.

Tukker, A., de Koning, A., Wood, R., Hawkins, T., Lutter, S., Acosta, J., Rueda Cantuche, J.M., Bouwmeester, M., Oosterhaven, J., Drosdowski, T., Kuenen, J., 2013. EXIOPOL Development and Illustrative Analyses of a Detailed Global MR ER SUT/IOT. Economic Systems Research 25, 50-70.

Tukker, A., Dietzenbacher, E., 2013. Global Multiregional Input-Output Frameworks: an Introduction and Outlook. Economic Systems Research 25, 1-19.

Wiedmann, T., Wood, R., Minx, J., Lenzen, M., Guan, D., Harris, R., 2010. A Carbon Footprint Time Series of the UK - Results From a Multiregion Input-Output Model. Economic Systems Research 22, 19-42.

Wilting, H., 2012. Sensitivity And Uncertainty Analysis In MRIO Modelling; Some Empirical Results With Regard To The Dutch Carbon Footprint. Economic Systems Research iFirst, 1-31.

Xu, Y., Dietzenbacher, E., 2014. A structural decomposition analysis of the emissions embodied in trade. Ecological Economics 101, 10-20.

Zhang, H., Chen, X., 2008. An Extended Input-Output Model on Education and the Shortfall of Human Capital in China. Economic Systems Research 20, 205-221.

\section{APPENDIX A}

In section 2.3 we note that the wages and profit components of gross value added are not available for the Rest of the World Region. Consequently the Western Euopean Textiles and Clothing wages and profit production footprints presented in the main text do not include contributions from the Rest of the World. Here we present the results of a sense check for the Western Euopean Textiles and Clothing wages and profit production footprints. Our sense check takes the form of a comparison of the Western Euopean Textiles and Clothing Income production footprint with the Western Euopean Textiles and Clothing Income-RoW production footprint. The Income production footprint is the sum of the wages and profit production footprints and represents gross value added generated at every stage of the value chain outside of the Rest of the World. The Income-RoW production footprint represents the gross value added generated at every stage of the value chain, including the Rest of the World region. 
Figure A1 shows trends in the Western Euopean Textiles and Clothing Income and Income-RoW production footprints at the aggregate level. Trends are identical until 1999, when the Income production footprint falls more quickly than the Income-RoW production footprint. This illustrates that value added declined less rapidly in the RoW region than in the other model regions. After 2001, the Income-RoW production footprint and Income production footprint recovered at similar rates until 2007 when growth in the Income production footprint was slower than growth in the Income-RoW production footprint. This suggests that between 2007 and 2008 value adding activities in RoW grew faster than the regional average.

Figure A2 shows the regional contributions to the Income and Income-RoW production footprints. By definition, all trends are identical apart from the Other less affluent nations region, which includes the Rest of the World region. Figure A2 confirms the results of Figure $A 1$, that relative to other regions, contributions to gross value added fell more slowly in the Rest of the World until 1999 and then began to grow before any other region. Figure A2 also highlights that gross value addition in the Rest of the World did experience relatively high growth rates in the 2007-2008 period.

Together, Figures A1 and A2 suggest that the wages and profit production footprints are underestimated. However, it is also clear that overall trends remain relatively unaffected. That said, we would expect production in the Rest of the World region (which includes, for example, Cambodia and Bangladesh) to be Labour rather than capital intensive. Hence we would expect most of the value added in this region to be in the form of wages and as a result, the sense check implies that not including contributions from the Rest of the World region had the biggest effect on the wages production footprint.

\section{APPENDIX B}

Table B1 Sector classification system correspondence table

$\begin{array}{lll}\text { Mair, Druckman, } & \text { WIOD } & \text { NACE } \\ \text { Jackson } 2014 & & \text { Codes }\end{array}$

$\begin{array}{lll}\text { Agriculture } & \text { Agriculture } & \text { AtB }\end{array}$

Energy and Resources Mining and Quarrying, Coke; Refined C;23;E

Petroleum and Nuclear Fuel; Electricity, 


\begin{tabular}{|c|c|c|}
\hline & Gas and Water Supply & \\
\hline Textiles and Clothing & Textiles and Textile Products & $17 \mathrm{t} 18$ \\
\hline \multirow[t]{18}{*}{ Other Manufactures } & Food, Beverages and Tobacco; & $15 \mathrm{t} 16$ \\
\hline & Leather, Leather and Footwear; Wood & 19;20; \\
\hline & and Products of Wood and Cork; Pulp, & $21 \mathrm{t} 22 ; 24$ \\
\hline & Paper, Paper , Printing and Publishing; & $25 ; 26$ \\
\hline & Chemicals and Chemical Products; & $27 t 28 ; 29$ \\
\hline & Rubber and Plastics; Other Non-Metallic & $30 t 33$ \\
\hline & Mineral; Basic Metals and Fabricated & $34 \mathrm{t} 35$ \\
\hline & Metal; Machinery, Nec; Electrical and & $36 \mathrm{t} 37 ; \mathrm{F} ; 50$ \\
\hline & Optical Equipment; Transport & $51 ; 52$ \\
\hline & Equipment; Manufacturing, Nec; & \\
\hline & Recycling; Construction; Sale, & \\
\hline & Maintenance and Repair of Motor & \\
\hline & Vehicles and Motorcycles; Retail Sale of & \\
\hline & Fuel; Wholesale Trade and Commission & \\
\hline & Trade, Except of Motor Vehicles and & \\
\hline & Motorcycles; Retail Trade, Except of & \\
\hline & Motor Vehicles and Motorcycles; Repair & \\
\hline & of Household Goods & \\
\hline \multirow[t]{11}{*}{ Services } & Hotels and Restaurants; Inland & $\mathrm{H} ; 60 ; 61$ \\
\hline & Transport; Water Transport; Air & $62 ; 63 ; 64 ;$ \\
\hline & Transport; Other Supporting and & $\mathrm{J} ; 70$ \\
\hline & Auxiliary Transport Activities; Activities & 71t74; L; M; \\
\hline & of Travel Agencies; Post and & $\mathrm{N} ; \mathrm{O} ; \mathrm{P}$ \\
\hline & Telecommunications; Financial & \\
\hline & Intermediation; Real Estate Activities; & \\
\hline & Renting of M\&Eq and Other Business & \\
\hline & Activities; Public Admin and Defence; & \\
\hline & Compulsory Social Security; Education; & \\
\hline & Health and Social Work; Other & \\
\hline
\end{tabular}


Community, Social and Personal

Services; Private Households with

Employed Persons 

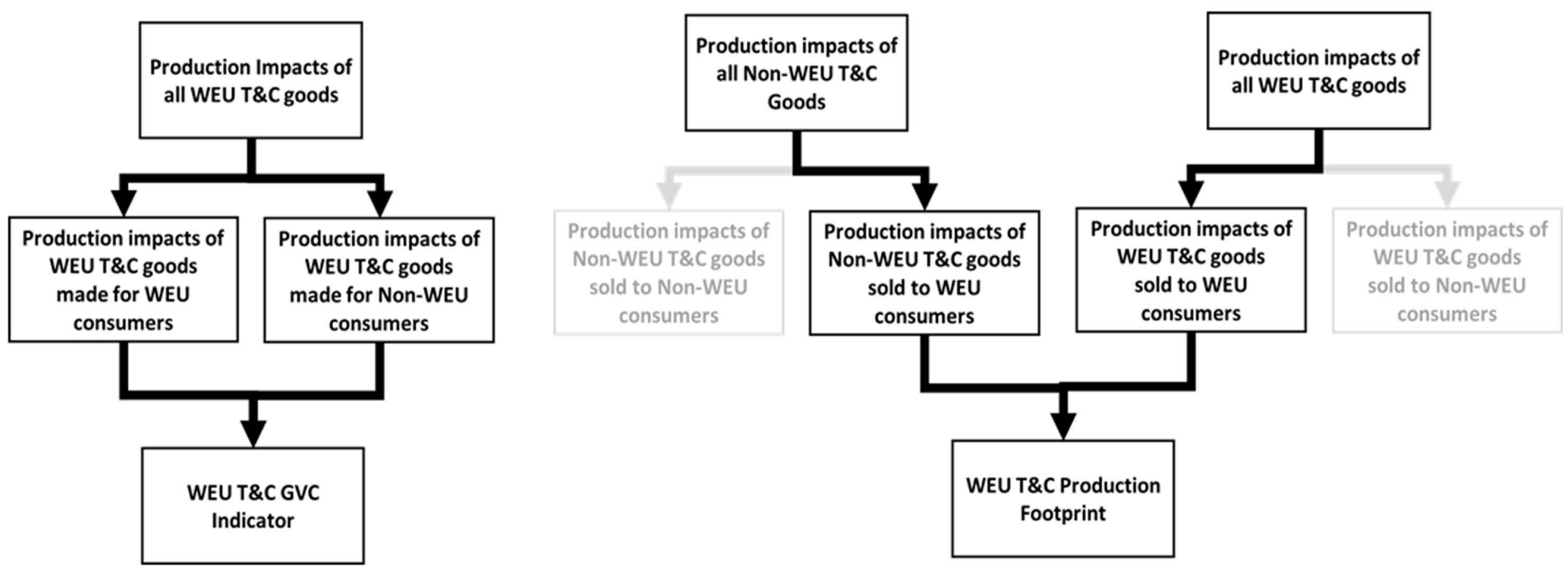


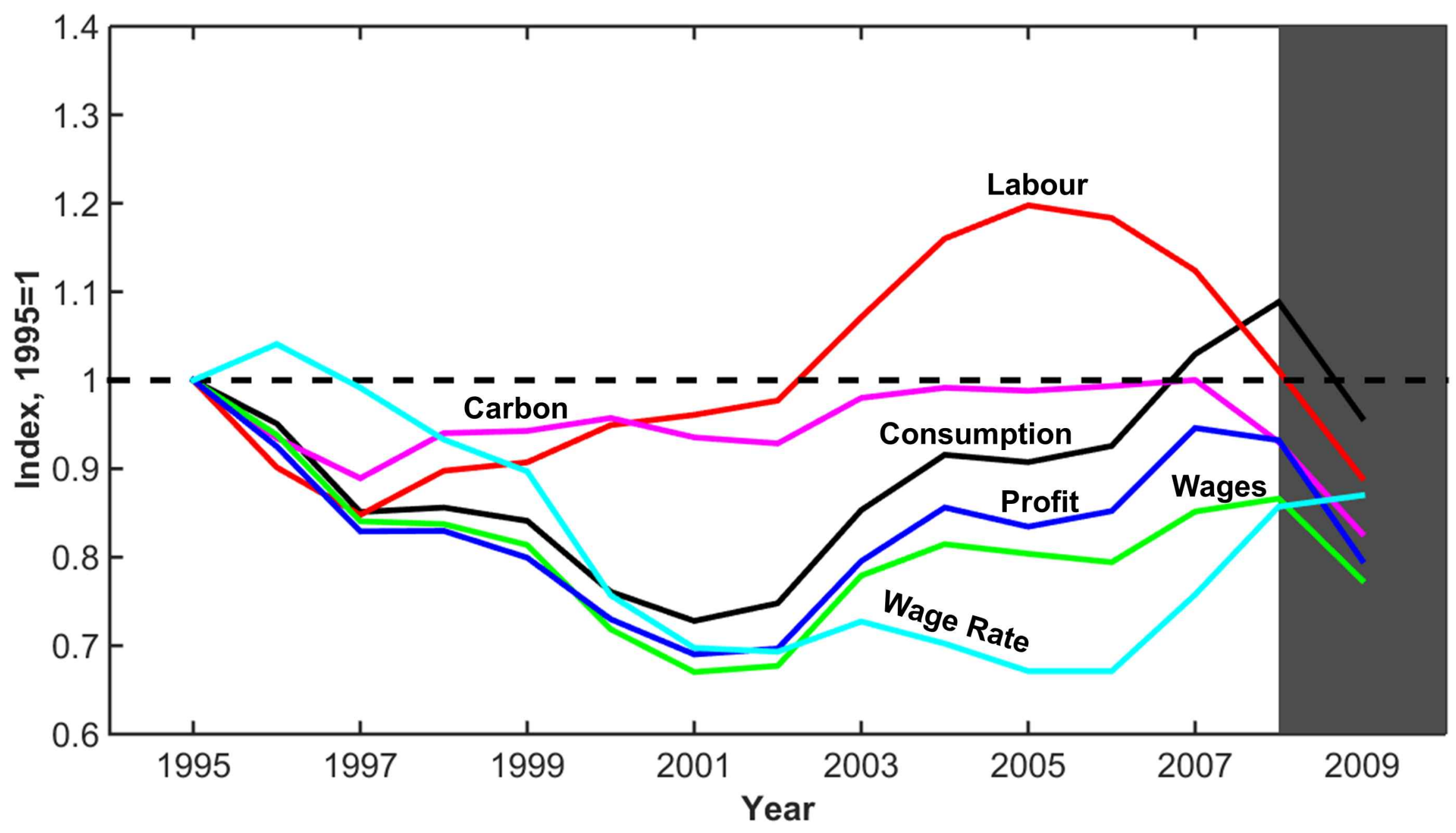




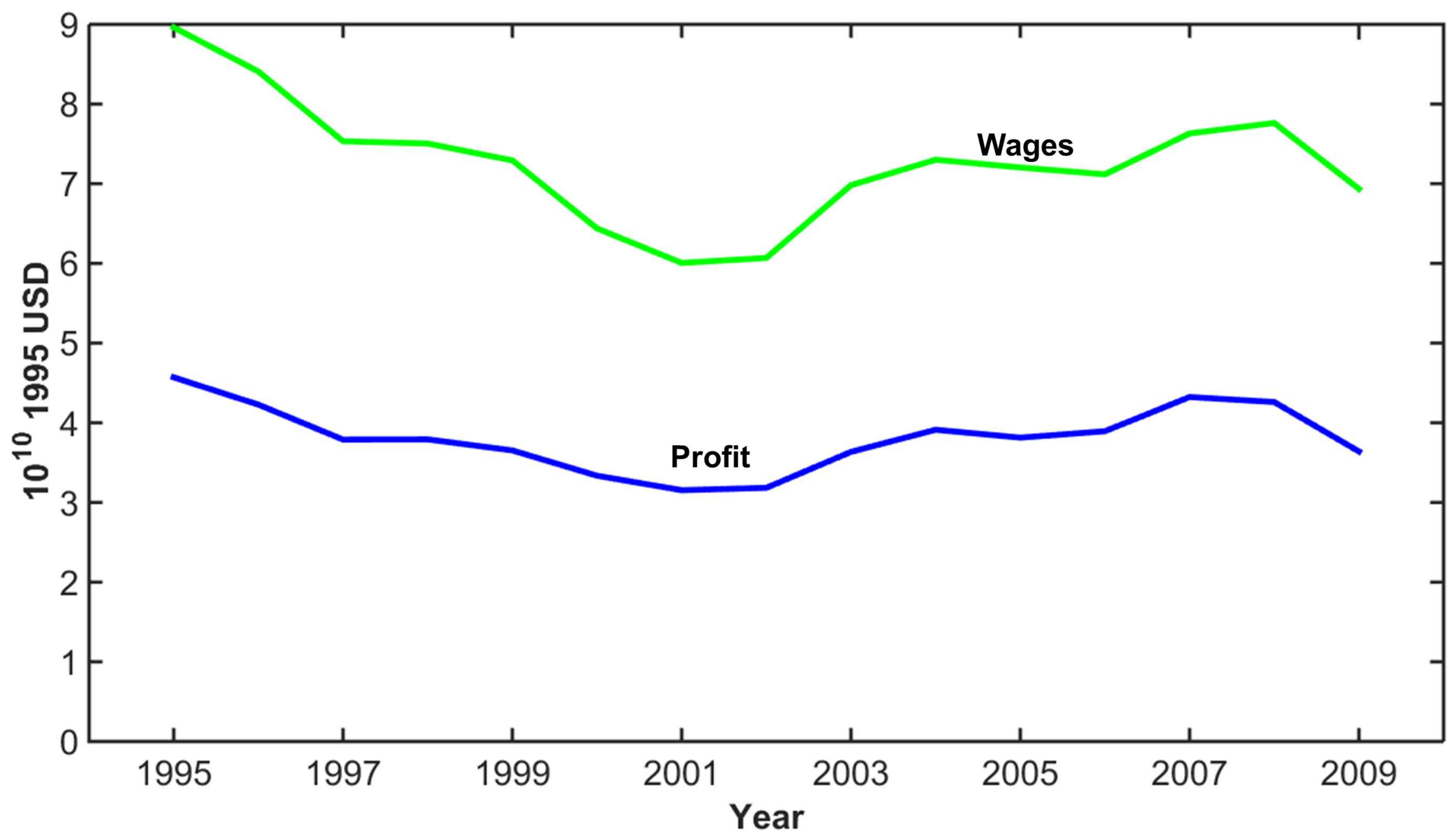



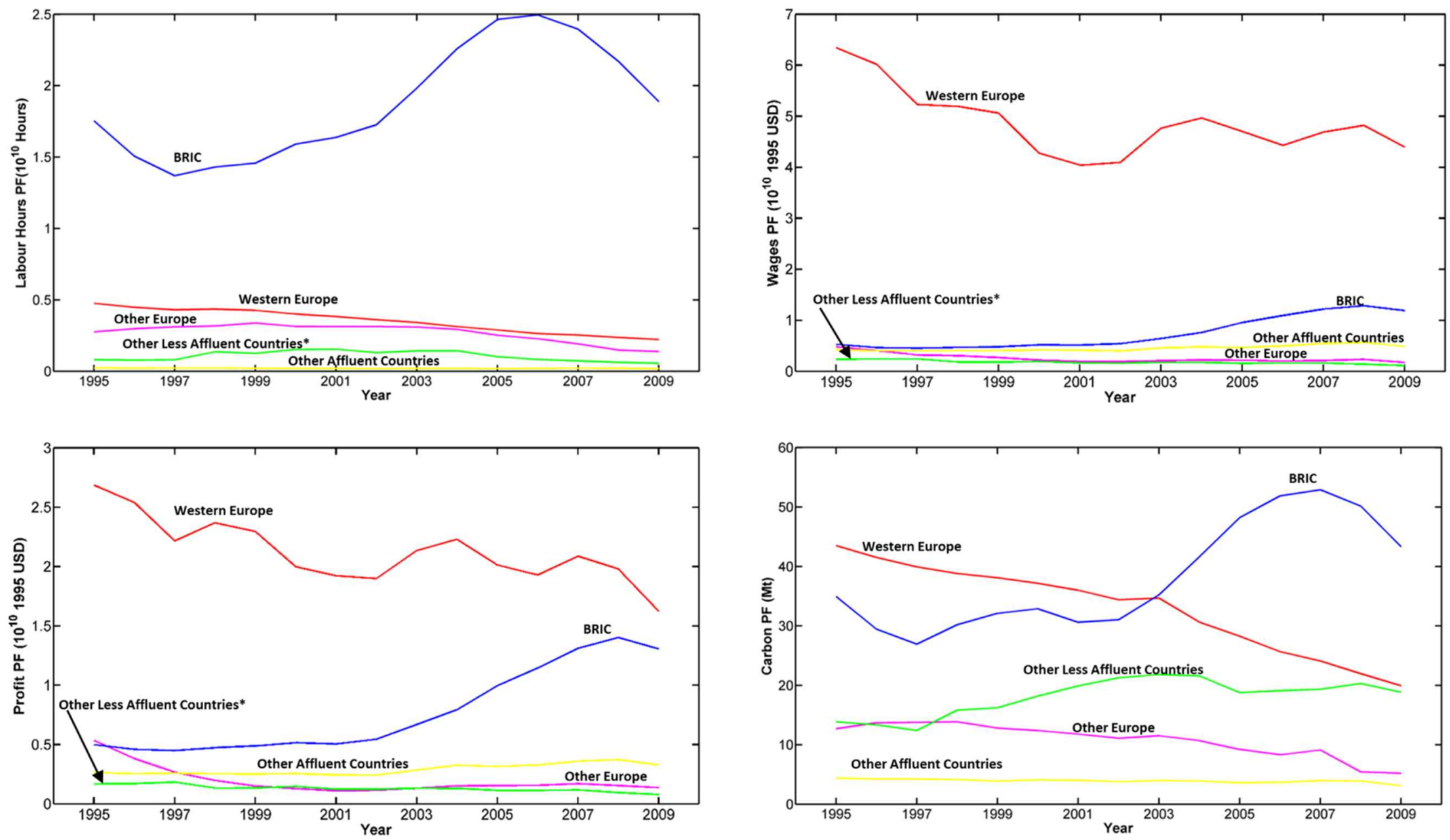


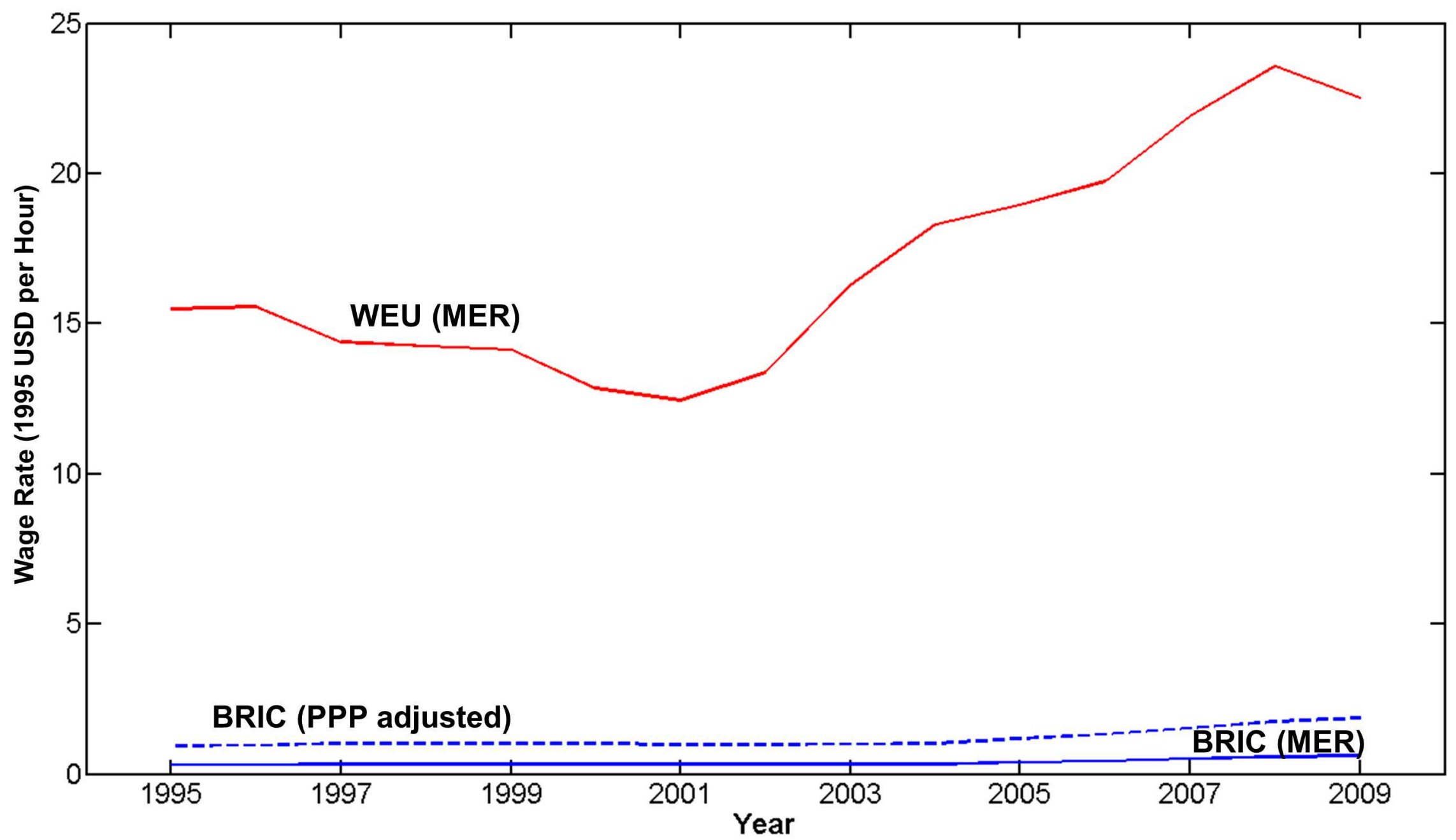



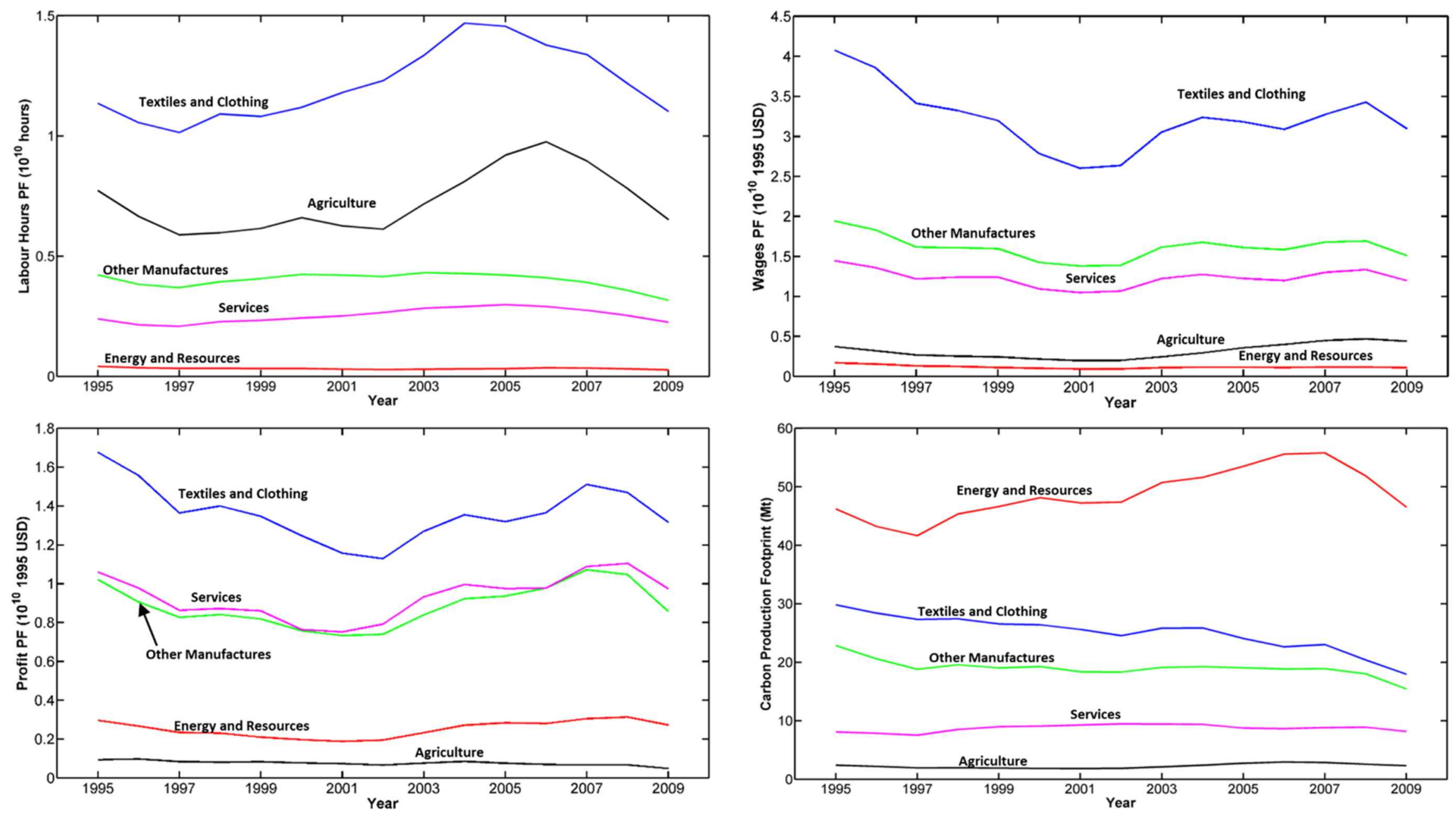


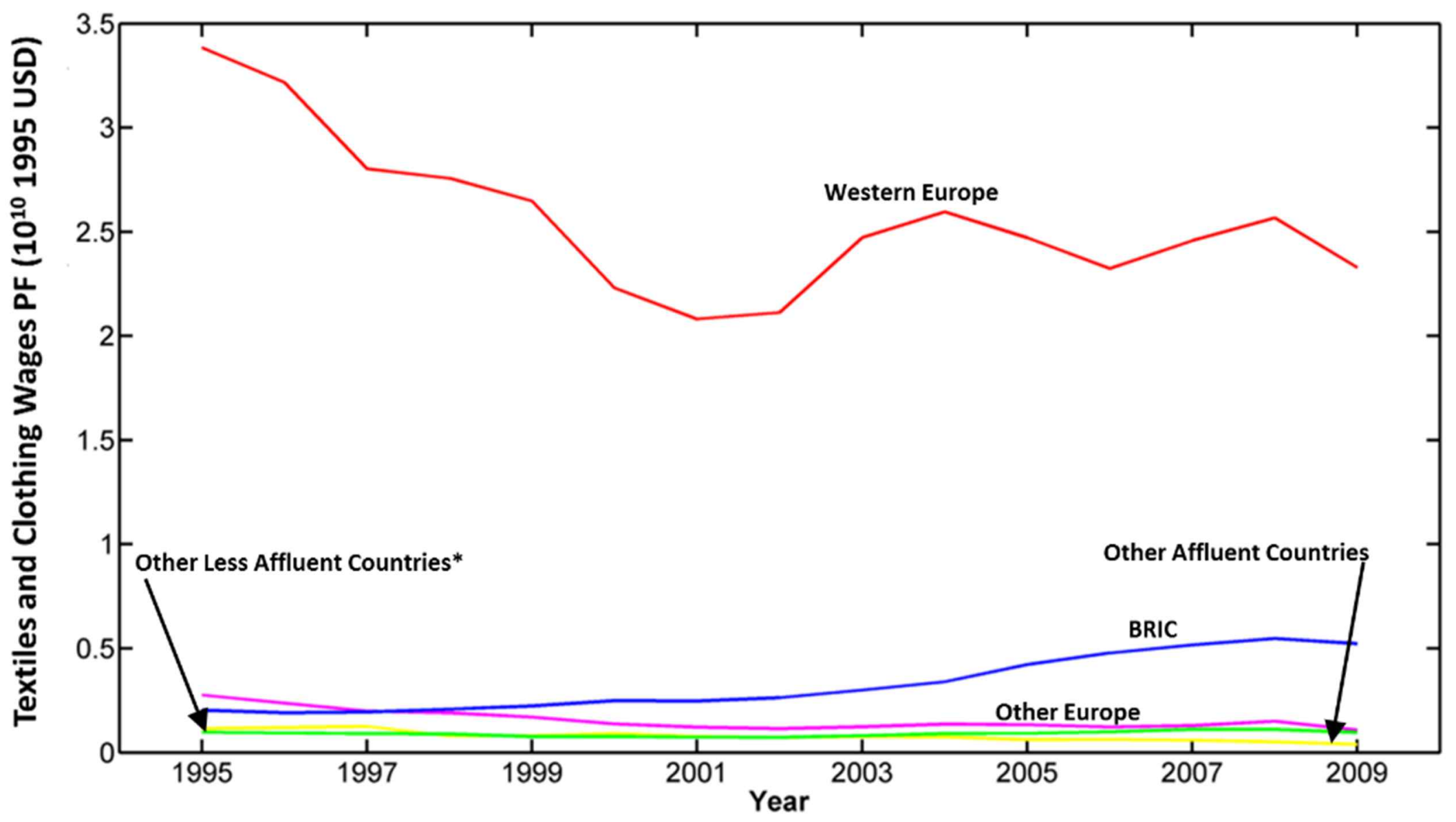




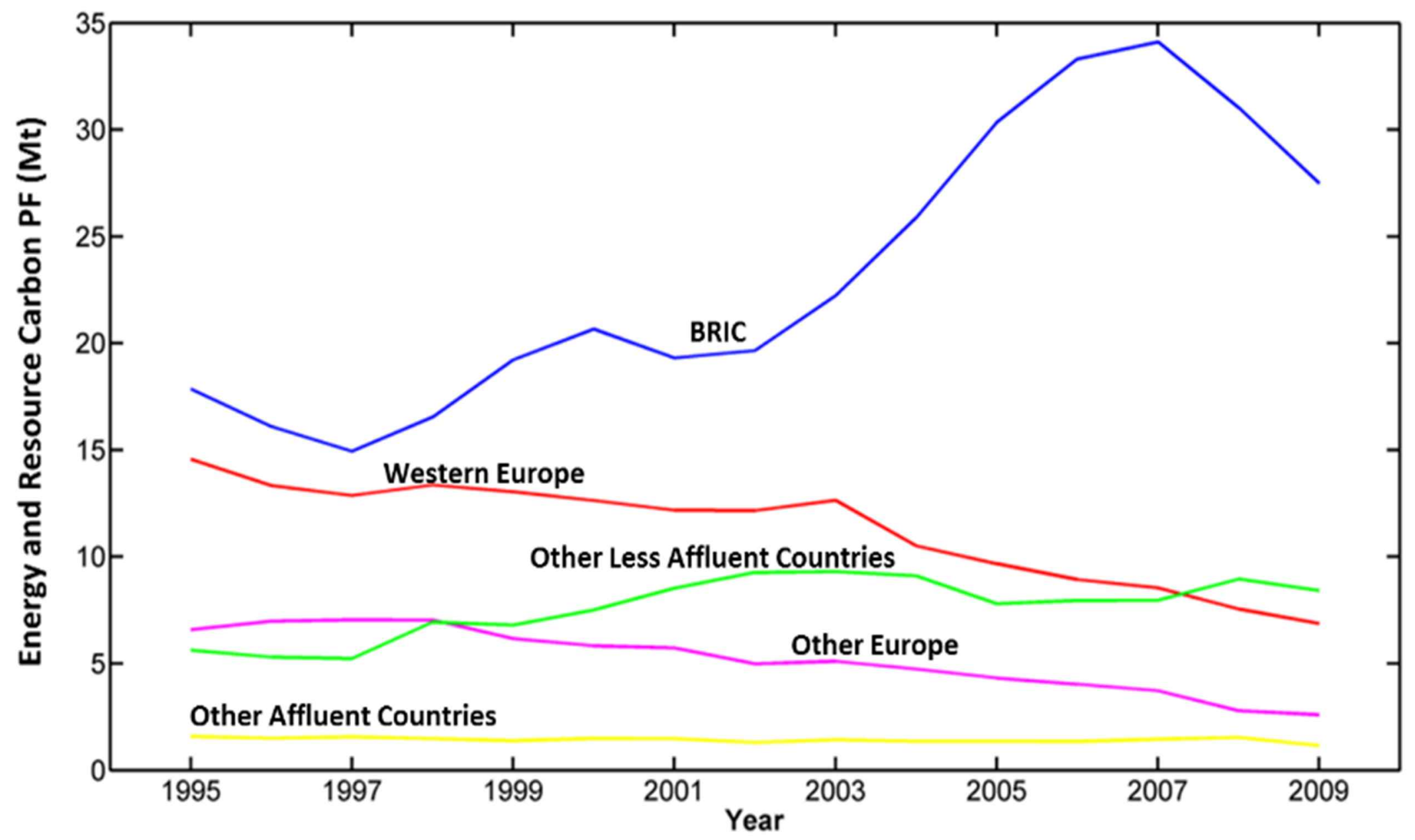




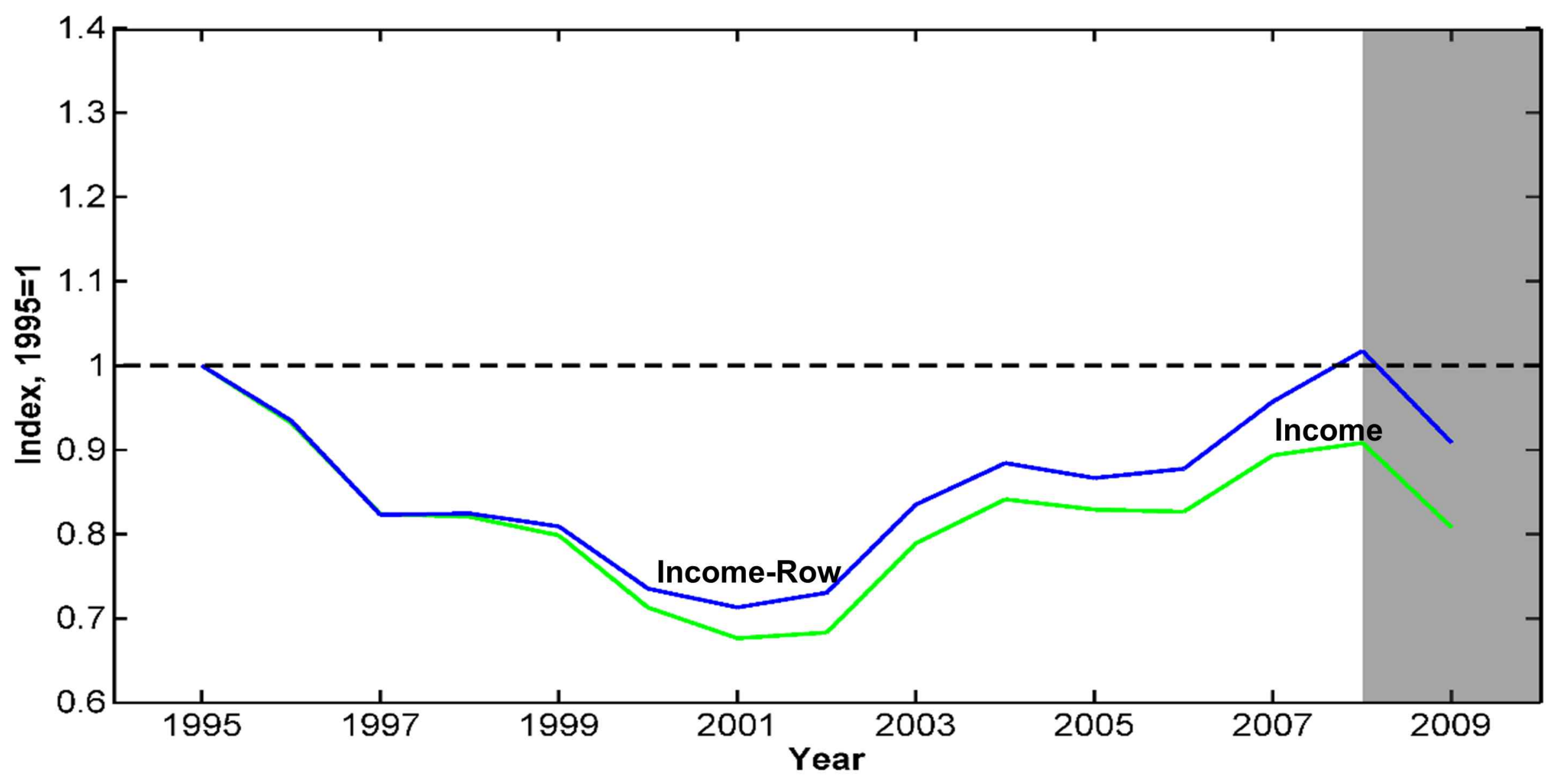




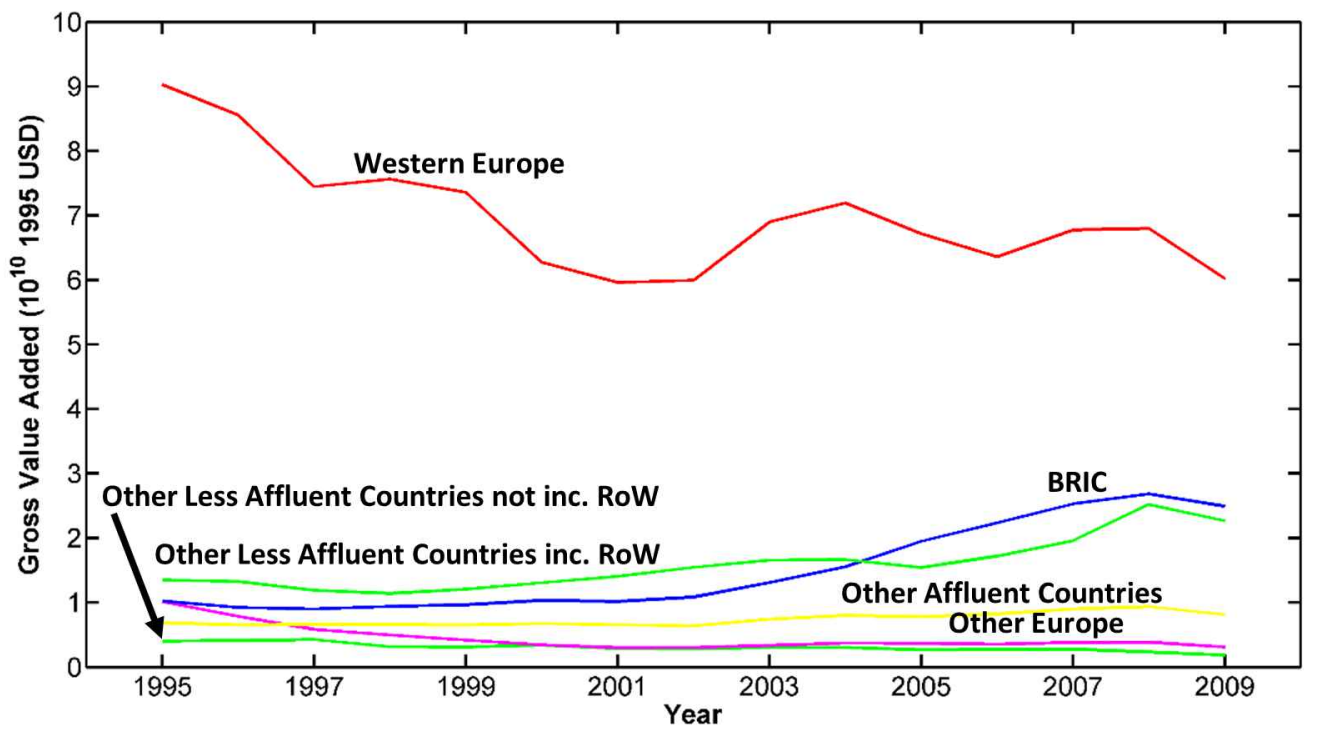

